\title{
Novel Mega Best-Seller Karya Luluk HF Mariposa dalam Kajian Resepsi Sastra
}

\section{'Mariposa' Luluk HF's Mega Best-Seller Novel in Reception Study}

\author{
Tania Intan ${ }^{1}$ dan Muhamad Adji ${ }^{2}$ \\ Fakultas Ilmu Budaya, Universitas Padjadjaran
}

Pos-el: tania.intan@unpad.ac.id ${ }^{1}, \underline{\text { m.adji@unpad.ac.id }}{ }^{2}$

\begin{abstract}
Abstrak
Penelitian ini membincangkan resepsi pembaca novel mega best-seller berjudul Mariposa karya Luluk HF. Tujuan penelitian ini adalah untuk (1) menguraikan tanggapan pembaca, (2) mendeskripsikan horizon harapan pembaca, serta (3) memaparkan faktor-faktor penyebab perbedaan tanggapan dan horizon harapan pembaca novel Mariposa. Metode yang diaplikasikan adalah deskriptif kualitatif. Penelitian ini menggunakan pendekatan estetika resepsi yang berupaya mencari pola-pola resepsi yang konsisten sebagai cerminan cara pembaca menanggapi teks. Data penelitian terdiri dari teks-teks yang memuat tanggapan dua puluh orang responden dari sumber data berupa situs pembaca Goodreads. Hasil penelitian yang didapat adalah sebagai berikut. Pertama, tidak semua pembaca menanggapi secara positif unsur-unsur intrinsik novel, terutama penokohan protagonis perempuan yang dianggap menunjukkan perilaku agresif dengan motif percintaan. Kedua, sebagian besar horizon harapan pembaca tidak sesuai dengan realita yang disajikan dalam Mariposa. Pembacaan umumnya dilatarbelakangi oleh motivasi rasa ingin tahu karena pelabelan hiperbolis terhadap novel, rekomendasi dari teman, serta wacana filmisasi novel. Ketiga, faktor-faktor penyebab perbedaan atau kesesuaian horizon harapan pembaca terhadap novel Mariposa adalah pengetahuan tentang sastra, pengetahuan tentang kehidupan, serta pengalaman membaca karya sastra.
\end{abstract}

Kata-kata kunci: resepsi sastra, tanggapan pembaca, horizon harapan, mariposa

\begin{abstract}
This study discusses the reception of readers of the mega best-seller novel entitled Mariposa by Luluk HF. The purpose of this study is to (1) describe the reader's responses, (2) describe the horizon of readers' expectations, and (3) describe the factors that cause differences in responses and the horizon of expectations of readers of Mariposa's novel. The method applied is descriptive qualitative. This study uses a reception aesthetic approach that seeks to find consistent reception patterns as a reflection of the way the reader responds to the text. The research data consisted of texts containing the responses of twenty respondents from the data source in the form of the Goodreads reader site. The research results obtained are as follows. First, not all readers respond positively to the intrinsic elements of the novel, especially the characterization of the female protagonist who is considered to show aggressive behavior with a love motive. Second, most of the horizons of readers' expectations do not match the reality in Mariposa. Readings are generally motivated by curiosity because of the hyperbolic labeling of the novel, recommendations from friends, and the discourse of filming the novel. Third, the factors that cause the difference or suitability of the horizon of readers' expectations for the Mariposa novel are knowledge of literature, knowledge of life, and experience of reading literary works.
\end{abstract}

Keywords: reception, reader response, hope horizon, Mariposa 


\section{PENDAHULUAN}

Novel Mariposa yang telah dibaca lebih dari 100 juta kali (Admin, 2021) atau disebutkan sumber lain sekitar 130 juta kali (HF, 2018a), merupakan karya kedua dari penulis Luluk HF. Karya fiksi remaja tersebut dibaca, terutama oleh para pengguna Wattpad dan mendapatkan banyak komentar positif dari mereka (Admin, 2020). Ketika diterbitkan menjadi buku oleh Coconut Books, Mariposa pun sukses terjual hingga 8.000 eksemplar dalam sehari.

Luluk HF lahir pada tanggal 14 Juni 1995, dengan nama asli Hidayatul Fajriah (Amalina, 2021). Penulis ini menjelaskan bahwa kata Mariposa berasal dari bahasa Spanyol yang berarti 'kupu-kupu.' Secara filosofis, kupu-kupu pada umumnya akan lari ketika dikejar, namun akan mendekat saat dibiarkan (Khalid, 2020). Mariposa (2018b) berkisah tentang pengejaran tokoh utama perempuan bernama Acha yang sangat menyukai laki-laki bernama Iqbal yang perilakunya menyerupai kupu-kupu yang sulit ditangkap.

Novel Mariposa (2018), yang terdiri dari 496 halaman memiliki sampul berwarna merah jambu dan bergambar seekor kupu-kupu, dipilih sebagai objek penelitian. Latar belakang pemilihan novel tersebut, selain karena jumlah pembacanya yang relatif sangat banyak, juga karena dianggap memiliki kekuatan dari segi cerita dibandingkan dengan karya fiksi remaja lainnya. Mariposa juga dinilai fenomenal, sebagaimana ditunjukkan melalui klaim yang tertulis pada sampulnya yaitu: "Rekor Novel dengan Jumlah Pembaca Terbanyak," "Segera difilmkan", serta "Telah dibaca 60 juta kali di Wattpad" (HF, 2018b).
Peneliti menemukan sejumlah kajian terdahulu yang menggunakan novel Mariposa sebagai objek telaah, seperti yang dilakukan Mazaya dkk (2020) yang mempelajari struktur intrinsik karya tersebut. Penelitian tersebut menemukan bahwa tema utama novel Mariposa adalah persahabatan dan percintaan, serta cerita yang digerakkan terutama oleh enam tokoh remaja. Sementara itu, Fitriani (2019) mengupas perwatakan tokoh dalam novel tersebut, dan Fajriyah \& Marsudi (2021) membahas dampak media sosial Instagram dalam mempromosikan novel Mariposa.

Berbeda dengan kajian-kajian terdahulu, penelitian ini lebih berfokus pada resepsi pembaca novel Mariposa yang dilakukan dengan mengelaborasi tanggapan dan horizon harapan pembaca dalam situs Goodreads. Penelitian ini juga bertujuan untuk mengungkap faktor-faktor penyebab perbedaan atau kesesuaian di antara tanggapan dan horizon harapan pembaca.

Dalam penelusuran peneliti, kajian dengan menggunakan pendekatan resepsi telah cukup banyak ditemukan, sebagaimana telah dilakukan oleh Intan (2019a), Saraswati (2011), Munaris (2011), Intan (2019b), Sari (2018), dan Dermawan (2014). Namun, dalam penelusuran peneliti, novel Mariposa belum pernah dikaji dalam perspektif resepsi sehingga penelitian ini dilanjutkan. Penelitian terhadap novel Mariposa dianggap penting karena dapat membuktikan alasan dari kelayakan buku tersebut di mata para pembacanya sebagai sebuah karya yang sangat digemari sehingga sudah sepantasnya meraih predikat mega best-seller.

Menurut Wulan (2013), suatu karya dinyatakan best-seller jika terjual lebih dari 
3000 eksemplar dalam waktu tiga bulan sebagaimana disebutkan oleh penerbit Gramedia Pustaka Utama. Dengan angka penjualan yang melampaui standar tersebut, tidak mengherankan jika novel Mariposa kemudian dilabeli sebagai "mega best-seller" dan menjadi salah satu ikon dalam sastra remaja populer di Indonesia.

\section{LANDASAN TEORI}

Resepsi sastra, menurut Pradopo (1986), adalah cabang ilmu sastra yang berhubungan dengan tanggapan pembaca terhadap karya sastra. Ilmu ini kerap disebut sebagai rezeptionaesthetic atau diterjemahkan sebagai (a) literary response, (b) aesthetic of reception, atau (c) resepsi sastra.

Pada prinsipnya, resepsi sastra berpijak pada cara pembaca memberikan makna terhadap karya yang dibacanya sehingga dapat memberikan reaksi atau apresiasi tertentu. Apresiasi sendiri dijelaskan Sayuti dalam Lubis dan Nurelide (2019), sebagai hasil usaha membaca dalam mencari dan menemukan nilai hakiki karya melalui pemahaman dan penafsiran sistematik yang dapat dinyatakan dalam bentuk tertulis.

Munaris (2011) menyatakan bahwa pembaca memiliki otonomi untuk memaknai teks karena penafsiran dan pemaknaan merupakan hasil dialogis antara pembaca dan teks meskipun terkadang pembaca masih mempertimbangkan keberadaan penulis.

Dalam pandangan Barthes, teks harus mandiri dan terlepas dari penulisnya, karena sebagaimana dinyatakan prinsip anonimitas, the author is dead. Dengan matinya penulis, maka pembaca pun menjadi hidup (Munaris, 2011).
Menurut teori resepsi, suatu teks baru memiliki makna bila sudah terhubung dengan pembaca. Teks membutuhkan kesan (wirkung) yang tidak mungkin ada tanpa pembaca. Resepsi juga memberikan kebebasan pada pembaca untuk memaknai teks meskipun kebebasan tersebut tidak sempurna karena selalu ada unsur-unsur yang membatasinya (Junus, 1985).

Untuk dapat menafsirkan dan memaknai teks, pembaca harus memiliki bahan dasar untuk menunjang proses tersebut. Karya sastra dikonkretisasi melalui penerimaan pembaca sehingga meninggalkan wirkung. Pembaca pun akan merekonstruksinya dengan bantuan imajinasi yang memungkinkannya melihat karya sastra dalam hubungan yang lebih luas. Imajinasi pembaca ini dimungkinkan oleh keakrabannya dengan tradisi sastra dan kesanggupannya dalam memahami keadaan pada masa itu atau masa sebelumnya (Junus, 1985). Melalui wirkung itulah, pembaca dapat menyatakan penerimaannya, baik dalam bentuk kritik/komentar maupun dalam bentuk karya lain yang berhubungan atau bertentangan, parodi, demitefikasi, dan sebagainya (Intan, 2019a).

Tanggapan pembaca dapat berbeda satu dengan yang lainnya, karena karya sastra selalu memberikan wajah yang berbeda pada pembaca yang satu dengan yang lainnya, selalu memberikan orkestrasi yang berbeda dari generasi yang satu ke generasi yang berikutnya (Jauss, Bahti, \& De Man, 2010). Perbedaan tersebut disebabkan oleh dua hal yang menjadi dasar teori estetika resepsi, yaitu prinsip horizon harapan dan prinsip tempat terbuka (Pradopo, 2007)

Secara sederhana, horizon harapan adalah bayangan yang dimiliki pembaca 
sebelum membaca karya sastra. Menurut Ratna (2007), horizon harapan (erwartungshorizont) merupakan citra, cakrawala, dan harapan pembaca yang berubah secara terus menerus, yang timbul sebagai akibat dari pembacaan terdahulu. Bila wujud harapan pembaca sesuai dengan wujud karya sastra yang dibacanya, pembaca akan menerimanya dengan mudah. Sebaliknya, jika tidak sesuai dengan wujud harapannya, pembaca akan bereaksi dengan sikap antusias atau bahkan menolak. Jika sebuah karya sastra tidak ditanggapi oleh suatu generasi, hal ini menunjukkan bahwa karya itu hanya menjadi milik masa lalu yang tidak lagi memiliki nilai sejarah (Intan, 2019a).

Menurut Segers (1978), horizon harapan pembaca ditentukan oleh tiga kriteria. Pertama, oleh norma-norma yang terpancar dari teks-teks sebelumnya. Kedua, oleh pengetahuan dan pengalaman atas teks yang telah dibaca. Ketiga, oleh pertentangan antara fiksi dan kenyataan, yaitu kemampuan pembaca untuk memahami karya sastra melalui horizon sempit dari harapan sastra maupun horizon luas dari pengetahuannya tentang kehidupan. Perbedaan tanggapan pembaca selain ditentukan oleh horizon harapan, juga disebabkan oleh tempat terbuka dalam karya sastra. Prinsip tersebut berhubungan dengan sifat karya sastra yang multitafsir atau polyinterpretable.

Dengan demikian, jelas bahwa dalam penelitian resepsi sastra, yang dikaji adalah tanggapan pembaca selain horizon harapan. Dalam telaah resepsi, terdapat dua bentuk kajian yaitu (1) resepsi secara sinkronis dan (2) resepsi secara diakronis. Bentuk pertama meneliti karya sastra dalam hubungannya dengan pembaca sezaman. Bentuk kedua dianggap lebih rumit karena melibatkan pembaca sepanjang sejarah (Ratna, 2015).

\section{METODE PENELITIAN}

Penelitian ini menggunakan metode deskriptif kualitatif dengan tujuan menggambarkan dan menginterpretasi objek penelitian dengan apa adanya. Jenis penelitian ini memanfaatkan kekuatan analisis yang mendalam serta terperinci, sekaligus luas dan holistik. Oleh karena itu, kekuatan nalar merupakan satu-satunya sumber daya untuk menganalisis seluruh proses penelitian (Arikunto, 2010).

Pendekatan yang digunakan dalam penelitian ini adalah metode resepsi sastra, yaitu merekonstruksi bermacam-macam konkretisasi karya sastra dalam masa sejarahnya dan meneliti hubungan di antara konkretisasi-konkretisasi tersebut (Vodicka, 1964). Teeuw (1984) menjelaskan tiga metode penelitian resepsi sastra, yaitu (1) penelitian resepsi sastra eksperimental, (2) penelitian resepsi sastra melalui kritik sastra dan penciptaaan karya baru, serta (3) penelitian resepsi intertekstual. Perbedaan di antara ketiganya adalah penelitian (1) dilakukan untuk resepsi saat ini, penelitian (2) dilakukan secara sinkronik atau diakronik, sedangkan penelitian (3) dilakukan dengan cara mengomparasi karya-karya yang memiliki kaitan intertekstual. Penelitian ini menggunakan metode yang kedua, yang dilakukan secara sinkronik, yaitu meneliti resepsi sastra dalam satu kurun waktu atau satu periode saja. Dalam tulisan ini, tanggapan pembaca yang dikaji adalah dari pembaca yang menanggapi novel Mariposa dalam periode bulan Januari tahun 2019 sampai dengan bulan Agustus tahun 2020 pada situs Goodreads. 
Data primer terdiri dari dua hal, yaitu (1) resepsi para responden yang merupakan pembaca novel Mariposa, dan (2) kata, frasa, dan kalimat yang dikutip dari novel Mariposa. Data primer pertama didapatkan dari apresiasi, komentar, atau reaksi tertulis dua puluh responden setelah membaca novel Mariposa. Kelompok responden ini didapatkan peneliti secara acak dari populasi pembaca novel Mariposa yang memberikan review 'ulasan' sebagai resepsi novel. Responden merupakan pembaca nyata yang telah membaca novel Mariposa.

Data kedua diperlukan untuk menguraikan narasi dan isi cerita novel Mariposa agar didapatkan pemahaman utuh tentang karya tersebut. Pengetahuan pembaca tentang aspek-aspek intrinsik novel akan membantu mereka dalam memberikan apresiasi terhadap karya tersebut.

Situs Goodreads

menunjukkan bahwa rata-rata pembaca memberikan poin $3.63 / 5$, dengan 947 ratings dan 141 review yang secara umum dapat diinterpretasikan sebagai apresiasi yang relatif positif atas novel Mariposa. Goodreads adalah situs jaringan sosial yang didirikan pada tahun 2009 yang mengkhususkan diri pada katalogisasi buku. Sama seperti aplikasi lainnya, situs ini memiliki konten friend, group, dan discussion, yang memungkinkan para pengguna saling berbagi rekomendasi buku bacaan dengan memberikan ulasan, komentar, serta peringkat.

\section{PEMBAHASAN}

Bagian ini membicarakan empat hal, yaitu (1) sinopsis cerita, (2) tanggapan pembaca, (3) horizon pembaca, dan (4) faktor-faktor penyebab perbedaan atau kesesuaian horizon harapan pembaca dengan novel Mariposa.

\section{Sinopsis Cerita Novel Mariposa}

Mariposa adalah novel remaja bertema percintaan atau teen lit yang mengangkat permasalahan kehidupan para tokoh yang berusia remaja, yaitu antara 16-18 tahun. Tokoh utama perempuan bernama Acha, panggilan untuk Natasha Kay Loovy, yang menyukai Iqbal Guanna Freedy. Acha yang cantik dan pandai digambarkan bersikap sangat asertif dalam mengejar pemuda tampan namun berhati dingin itu. Meskipun berkali-kali diabaikan dan tidak jarang dikasari, Acha tidak dapat menjauhi Iqbal. Lama-kelamaan laki-laki itu pun menyadari bahwa dirinya menyukai gadis yang cantik, baik, dan pintar tersebut.

Alur cerita yang bergerak progresif tanpa flash back seperti ditujukan untuk mendukung gagasan tekad kuat dan pantang mundur dari tokoh Acha. Narasi yang cenderung berpihak pada tokoh remaja perempuan itu dibawakan oleh orang ketiga di luar cerita yang mengetahui semua hal yang terjadi pada setiap tokoh. Pencerita omniscient seperti ini memiliki keleluasaan untuk memberi informasi pada pembaca untuk turut menjelajahi alam pikiran para tokoh dan dapat memahami alasan dari perilaku mereka.

Karena berkisah tentang konflik percintaan remaja dan dibaca lebih banyak oleh remaja, maka bahasa dan gaya penulisan yang digunakan pun cenderung tidak baku, nonformal, dan santai. Para tokoh remaja yang ditampilkan hidup di kota besar itu saling menggunakan sapaan "gue-lo" yang memperlihatkan keakraban.

Kegigihan Acha dalam mengejar cinta Iqbal ditunjukkan sepanjang kisah novel Mariposa, mulai dari memutuskan 
untuk pindah ke sekolah yang sama dengan laki-laki itu. Acha juga berani menyatakan cinta secara verbal maupun dalam bentuk perilaku yang sangat kentara pada Iqbal.

"Terus, mau lo apa?"

"Mau Acha?" tanya Acha balik penuh semangat. "Iqbal jadi pacar Acha. Mau kan?" [...]

"Iqbal mau nggak jadi pacar Acha?" tanya Acha lagi.

"Nggak," tolak Iqbal cepat.

(HF, 2018:29)

Seperti terobsesi, Acha meminta nomor telepon Iqbal, membawakannya makanan, sampai berpura-pura tenggelam agar mendapat perhatian pemuda itu. Dalam menghadapi sikap dingin Iqbal yang disukainya, Acha tetap tidak berputus asa dan terus menunjukkan kasih sayangnya kepada Iqbal.

Iqbal tak menjawab, langsung pergi begitu saja. Ia lagi-lagi mencampakkan Acha.

Acha menundukkan kepalanya, raut wajahnya bertambah sedih, "Susah banget dapetin hatinya Iqbal, itu hati apa semen? Kokoh banget, tak tertandingi. Tapi Acha nggak boleh nyerah. Nggak boleh!" Acha mengangkat kepalanya tegak. Ia kembali bersemangat.

(HF, 2018)

Setelah mengalami penolakan berkali-kali dari Iqbal, Acha pun memutuskan untuk menyerah dan mulai mempertimbangkan Juna yang sudah jelas menyukainya. Ketika itulah Iqbal merasa ada yang hilang dari dirinya. Akhir cerita menunjukkan bahwa setelah melalui berbagai peristiwa pelik, Iqbal menyadari bahwa sebenarnya ia menyukai Acha, namun merasa sulit ketika ingin mengungkapkannya. Cerita Mariposa pun ditutup sesuai dengan keinginan pembaca untuk menyatukan Acha dan Iqbal dalam hubungan percintaan.

\section{Tanggapan Pembaca terhadap Novel Mariposa}

Tanggapan pembaca novel Mariposa didapatkan dari situs Goodreads. Dua puluh responden yang dipilih secara acak mengungkapkan pendapat dan tanggapan mereka sebagai pembaca novel tersebut. Adapun gaya penulisan dalam mengungkapkan gagasan masing-masing, pada umumnya tidak menggunakan bahasa baku dan kerap bercampur dengan bahasa asing (bahasa Inggris). Dalam pembahasan, kutipan-kutipan ditulis sesuai dengan kondisi teks apa adanya.

Pada tabel 1 ditampilkan tanggapan responden atas unsur-unsur pembentuk novel Mariposa, yang dibatasi pada aspek alur, tokoh, tema, dan humor. Pembatasan tersebut didasari atas pemantauan unsur yang paling banyak dibahas dalam teks tanggapan pembaca pada situs Goodreads. Pada tabel 1, tanggapan pembaca ditunjukkan dengan simbol (+) untuk apresiasi positif dan simbol (-) untuk apresiasi negatif.

Dari tabel 1, dapat diketahui bahwa unsur intrinsik yang paling dominan diresepsi pembaca adalah tokoh (90\%), kemudian tema (75\%), alur (70\%), dan terakhir aspek humor (40\%).

Jumlah halaman dari novel Mariposa yang relatif tebal, yaitu 496, dinilai terlalu berlebihan karena menampilkan plot-plot yang dianggap tidak penting. Alur progresif dan cepat dari 
novel tersebut ternyata dinilai tidak cukup untuk menggerakkan cerita secara efektif dan logis. Responden Fanny menganggap bahwa "banyak plot holes yang ga masuk akal dan dipaksain", sedangkan Edeline menyebut bahwa "alur ceritanya berkesan lambat", sehingga akibatnya plot twist-nya tidak terasa (Rahajeng, 2020), dan berpotensi membuat pembaca jenuh.

\section{Tabel 1}

\section{Tanggapan Pembaca}

\begin{tabular}{llcccc}
\hline No & Responden & AL & TO & TE & HU \\
\hline 1 & Yasir J & + & - & + & - \\
\hline 2 & Leefe & - & - & + & \\
\hline 3 & Omnivoreader & & - & & \\
\hline 4 & Gichyle & - & - & - & + \\
\hline 5 & Dc dewi & & & - & \\
\hline 6 & Rei Reihana & & - & & - \\
\hline 7 & Fanny & + & - & + & + \\
\hline 8 & Anti & - & - & - & + \\
\hline 9 & Sasa & & - & + & \\
\hline 10 & Fernita & & - & & \\
\hline 11 & Affiraaa & + & & + & + \\
\hline 12 & Fujwara Asuka & & - & - & \\
\hline 13 & Vinda Zahro & + & + & + & \\
\hline 14 & Zella & - & - & + & \\
\hline 15 & Dyah & - & - & - & \\
& Puspitasari & & & & \\
\hline 16 & Maretasari Hill & + & - & - & \\
\hline 17 & Arika & + & + & + & + \\
\hline 18 & Anyelir & + & - & - & + \\
\hline 19 & CottonBlue & - & - & & \\
\hline 20 & Edeline & - & - & & \\
\hline \multicolumn{7}{l}{ Total } & 14 & 18 & 15 & 8 \\
\hline Persentase (+) & 50 & 11 & 53 & 75 \\
\hline Persentase (-) & 50 & 89 & 47 & 25 \\
\hline
\end{tabular}

$\begin{array}{ll}\text { Keterangan: } \\ \mathrm{AL} & =\text { Alur } \\ \mathrm{TO} & =\text { Tokoh } \\ \mathrm{TE} & =\text { Tema } \\ \mathrm{HU} & =\text { Humor } \\ + & =\text { Penilaian positif } \\ - & =\text { Penilaian negatif }\end{array}$

Seperti untuk mempertegas pandangan tersebut, Aprilia (2020) menyebutkan bahwa novel fenomenal tersebut mengecewakan karena "ceritanya ternyata begitu saja, ceritanya terkesan dipanjang-panjangkan, banyak adegan enggak penting yang terasa dipaksa nyempil". Persepsi para responden ini membuktikan bahwa alur dalam novel Mariposa tidak mendapatkan apresiasi positif.

Selain pernyataan tentang alur dan perguliran cerita yang dinilai lamban tersebut, mayoritas pembaca (sekitar 89\%) menganggap Acha sebagai sosok yang bucin "budak cinta" yang dapat diinterpretasikan sebagai perempuan yang dengan sengaja mengikatkan diri pada lakilaki yang disukainya dan bersikap agresif (alih-alih "asertif” yang berkonotasi lebih positif dalam konteks kepribadian).

Siswi SMA peserta olimpiade sekolah yang dianggap berperilaku "genit" dan kekanak-kanakan itu dinilai responden Anti membosankan dan mengganggu, dan bahkan dinobatkan sebagai "the most annoying heroine yang pernah aku baca di [antara] buku-buku lain" (Fujiwara Asuka). Kondisi tersebut dikritisi Leefe yang menyatakan "baru tahu karakter si Acha-acha nehi-nehi yang luar biasa agresif, kening saya langsung berkerut. For real, apa dia enggak punya malu sampai deketin Iqbal segitunya?". Rei Reihana juga menilai tokoh Acha sebagai tokoh yang lebay banget 'sangat berlebihan', sementara Zella menyebutnya "pemaksa, childish, dan egois gitu". Eksekusi penyajian tokoh yang tidak terlalu sukses terutama pada tokoh Acha ini membuat responden Gichyle menyatakan "gue benci banget sama karakternya. Especially, Acha."

Penilaian negatif yang mendominasi tanggapan pembaca atas tokoh Acha diimbangi oleh apresiasi positif responden Fanny atas tokoh Glen yang dianggapnya lucu dan mampu membuat tertawa, "karakter Glen ini sungguh suatu penyegaran di novel ini". Namun, tanggapan tersebut tampaknya 
tidak cukup memadai karena secara keseluruhan, penokohan dalam novel Mariposa dianggap buruk, tidak realistis, dan terlalu dipaksakan. "Acha pinter, Iqbal pinter. Fine. Dua2nya juara olimpiade? ММММММHН. Yeah, no. Ga tau ya, gw ngerasa itu lebay" (Fanny).

Sebagai protagonis laki-laki yang sangat kukuh menolak Acha, namun menjelang akhir cerita menerimanya, Iqbal pun tidak dinilai cukup baik. Ia diresepsi sebagai tokoh yang plinplan (Edeline).

Satu-satunya tanggapan positif dari pembaca terhadap tokoh Acha dan Iqbal datang dari responden Vinda Zahro. Ia memandang bahwa bahwa "Natasha Kay Loovi, perempuan cantik jelita yang naifnya jatuh cinta padanya (Iqbal). Tak ter-elakkan. Satu hal yang paling kusukai dari keduanya: sama-sama jenius, cerdas, otak encer, dan yang lain semacamnya". Konstruksi atas tokoh remaja perempuan itu dianggap wajar dan normal karena dipasangkan dengan sosok laki-laki yang juga berkualitas. Dengan pijakan itulah, tampaknya, menurut Vinda Zahro, cerita menjadi lebih menarik dan 'berimbang'.

Resepsi yang demikian banyak, meskipun negatif, terhadap tokoh Acha merupakan sesuatu yang logis karena perannya dalam cerita sangat dominan. Ketokohutamaan Acha, dibandingkan dengan Iqbal, misalnya, sesuai dengan kriteria yang ditetapkan Sayuti yang dikutip Munaris (2011), yaitu bahwa tokoh utama merupakan pihak yang paling banyak mengambil porsi dalam penceritaan. Peristiwa-peristiwa pun berputar di sekitar kehidupan tokoh tersebut.

Dari tabel 1 dan uraian tanggapan dalam situs Goodreads, pembaca novel Mariposa menganggap penggunaan tema percintaan remaja merupakan banalitas yang akhir ceritanya mudah ditebak, "ini mainstream bats. Cape lah gue ama cerita kek gini" (Gichyle) dan "adegan romancenya udah kayak cerita Wattpad lainnya. Jadi bisa ketebak gitu alurnya" (Affiraaa). Responden Rei Reihana pun menyepakati pandangan tersebut dengan menilai bahwa "(mem)baca novel ini bener2 pusing dan mual”.

Namun, Mariposa dan novel-novel remaja sejenis dianggap cukup menarik dan menghibur dalam kapasitasnya sebagai bacaan ringan untuk mengisi waktu luang. Hal ini disampaikan responden Vinda Zahro yang menganggap positif kegiatan membaca novel romance seperti Mariposa karena dapat "menambah kadar keromantisan tersendiri sama suami”.

Walaupun dianggap memiliki sejumlah kekurangan, eksplorasi aspek humor oleh pengarang cukup diapresiasi oleh pembaca, seperti Gichyle yang mengungkapkan bagaimana "Gue lumayan suka sama humornya", "Salut dg pemilihan jokes2nya yg bikin segar ceritanya" (Anti), dan "saya mengapresiasi juga bagaimana penulis mencoba melontarkan jokes-jokes receh khas zaman sekarang baik dalam narasi maupun dialog [..] sebagian besar jokes gagal..." (Yasir Jabry). Bahkan, responden Affiraaa menilai unsur humorlah yang menyelamatkan novel Mariposa, "[...] untung authornya pinter buat humor, adegan romancenya udah kayak cerita Wattpad lainnya".

Selain humor, hal lain yang dianggap menarik dari novel tersebut adalah "cover dan fontnya yang enak dibaca" (Rei Reihana). Sampul yang bergambar dan berwarna atraktif juga 
dianggap responden Zella sebagai terhadap novel Mariposa tentang kekuatan Mariposa.

Bagian sampul pun menjadi motivasi/alasan responden membaca karya tersebut. Selanjutnya, dibahas kesesuaian penting karena memuat tulisan "telah dibaca puluhan juta kali dan akan segera difilmkan" (Maretasari Hill). Selain itu, Rahajeng (2020) menjelaskan bahwa dalam Mariposa terdapat ilustrasi pada bab-bab tertentu yang membuat pembaca tidak (terlalu) jenuh.

Selain bagian sampul, trailer film Mariposa yang dipromosikan melalui berbagai media online dan menampilkan artis Angga Yunanda serta Adhisty Zara juga dianggap membantu pembaca novel dalam membangun imajinasi tentang tokoh-tokoh dalam kisah fiksi remaja tersebut.

Bagian analisis selanjutnya membahas horizon harapan pembaca atau ketidaksesuaian di antara horizon harapan dengan realita yang ditampilkan oleh novel.

\section{Horizon Harapan Pembaca terhadap Novel Mariposa}

Pada tabel 2 ditampilkan hasil rekapitulasi data mengenai motivasi membaca novel Mariposa yang menjadi pijakan penentuan horizon harapan pembaca. Selanjutnya, tanggapan pembaca dalam situs Goodreads diklasifikasi atas kesesuaian atau ketidaksesuaian di antara horizon harapan dengan kenyataan pada novel. Simbol (x) digunakan untuk menandai posisi horizon harapan pembaca, yaitu sesuai atau tidak sesuai.

Tabel 2

Horizon Harapan Pembaca

\begin{tabular}{|c|c|c|c|c|}
\hline No & Responden & Motivasi Membaca Novel & $\mathbf{S}$ & TS \\
\hline 1 & Yasir Jabry & Penasaran & & $\mathrm{X}$ \\
\hline 2 & Leefe & Ingin tahu mengapa booming & & $\mathrm{x}$ \\
\hline 3 & Omnivoreader & Penasaran & & $\mathrm{X}$ \\
\hline 4 & Gichyle & Ingin tahu karena akan difilmkan & & $\mathrm{x}$ \\
\hline 5 & Dc dewi & Tertarik embel-embel "telah dibaca 100 juta kali" & & $\mathrm{x}$ \\
\hline 6 & Rei Reihana & - & & $\mathrm{x}$ \\
\hline 7 & Fanny & Membayangkan filmnya akan menarik & $\mathrm{x}$ & \\
\hline 8 & Anti & Tertarik karena akan difilmkan dan label "mega best-seller" & & $\mathrm{X}$ \\
\hline 9 & Sasa & Penasaran dengan label "telah dibaca 120 juta kali" & $\mathrm{x}$ & \\
\hline 10 & Fernita M.H & - & & $\mathrm{X}$ \\
\hline 11 & Affiraaa & Ingin membaca bacaan ringan & $\mathrm{X}$ & \\
\hline 12 & Fujwara Asuka & Direkomendasi-kan teman & & $\mathrm{X}$ \\
\hline 13 & Vinda Zahro & Selalu tertarik dengan cerita romance & $\mathrm{x}$ & \\
\hline 14 & Zella & Direkomendasi-kan teman & & $\mathrm{X}$ \\
\hline 15 & Dyah Puspitasari & Ingin tahu & & $\mathrm{x}$ \\
\hline 16 & Maretasari Hill & $\begin{array}{l}\text { Melihat sampul dengan tulisan "telah dibaca puluhan juta } \\
\text { kali" dan akan difilmkan }\end{array}$ & & $\mathrm{x}$ \\
\hline 17 & Arika & Ingin tahu & $\mathrm{x}$ & \\
\hline 18 & Anyelir & - & & $\mathrm{x}$ \\
\hline 19 & Cotton Blue & Ingin tahu & & $\mathrm{x}$ \\
\hline \multirow[t]{3}{*}{20} & Edeline & Penasaran & & $\mathrm{x}$ \\
\hline & & Total & 5 & 15 \\
\hline & & Persentase & 25 & 75 \\
\hline
\end{tabular}

\section{Keterangan:}

$\mathrm{S} \quad=$ Sesuai dengan horizon harapan

TS = Tidak sesuai dengan horizon harapan

$\mathrm{x} \quad=$ Pilihan pembaca 
Dari tabel 2 diketahui bahwa motivasi pembaca membaca novel Mariposa terutama adalah karena perasaan ingin tahu dari 55\% pembaca, yang dipicu oleh klaim bahwa karya tersebut telah dibaca oleh sangat banyak orang (100 juta, 120 juta, atau puluhan juta).

Alasan dari pembacaan novel tersebut menurut $20 \%$ responden adalah karena akan difilmkan. Mereka membayangkan figur-figur selebriti muda yang akan memainkan peran Acha dan Iqbal sehingga merasa tertarik untuk membaca novelnya terlebih dahulu. Di Indonesia, novel yang diangkat ke layar lebar pada umumnya memang dinilai memiliki kisah yang menarik, seperti di antaranya novel Laskar Pelangi, Dua Garis Biru, Antologi Rasa, Dilan, dan Perahu Kertas.

Tabel 2 juga mengungkap bahwa sebanyak $15 \%$ tidak menjelaskan motivasi membaca novel Mariposa dan 10\% responden menyatakan bahwa karya itu ditawarkan oleh teman. On (2019) misalnya, merekomendasikan novel tersebut karena bercerita tentang perjuangan tokoh remaja seperti Iqbal dalam mencapai mimpinya untuk menjadi astronot. Mariposa juga, menurutnya, mengeksplorasi usaha Acha yang, meskipun mengalami masalah cinta, tetap memiliki semangat belajar tinggi dan meraih juara Olimpiade.

Dari tabel 2 diketahui bahwa 75\% responden menyampaikan ketidaksesuaian horizon harapan mereka dengan realita yang disajikan novel Mariposa. Hal tersebut terungkap misalnya melalui narasi responden Fujiwara Asuka yang mengakui dirinya membeli novel Mariposa karena mengikuti saran temannya yang menyebut "katanya buku ini bagus banget". Namun, kemudian responden ini menemukan bahwa "sumpah buku ini sama sekali ga memenuhi ekspektasiku”. Ekspektasi yang dimaksud adalah horizon harapan pembaca responden tersebut yang awalnya memandang buku itu berkualitas baik sebagaimana telah direkomendasikan oleh temannya. Penilaian serupa dinyatakan Maretasari Hill yang menyebutkan bahwa "setelah saya membacanya hingga beberapa lembar, logika saya rasanya diterpa deburan ombak yang begitu besar". Dalam review-nya, responden ini merasa seperti sangat tertipu oleh "tampilan dan kemasan yang begitu apik seperti itu”. Horizon harapan yang tinggi juga ditunjukkan responden Leefe, yang mengungkapkan bagaimana Mariposa "sukses membuat saya kecewa".

Pembahasan mengenai kesesuaian atau perbedaan horizon harapan pembaca terhadap novel Mariposa akan dibahas pada bagian berikut ini.

\section{Faktor-faktor Penyebab Perbedaan atau Kesesuaian Horizon Harapan Pembaca dengan Novel Mariposa}

Dariannisa (2020) mengungkapkan bahwa 'nama besar' Mariposa didukung oleh keberhasilan novel sebelumnya, EL, yang juga telah difilmkan dan mendapatkan penonton yang cukup banyak. Dengan demikian, tidak mengherankan bila banyak pembaca kemudian berharap menemukan hal yang baru dan lebih menarik di dalam Mariposa.

On (2019) merekomendasikan novel tersebut karena menurutnya cocok untuk remaja. Dalam Mariposa dinarasikan perjuangan para tokoh, baik Iqbal yang berusaha mencapai mimpinya 
untuk menjadi astronot, dan Acha yang tetap memiliki semangat belajar tinggi dan meraih juara Olimpiade meskipun mengalami masalah cinta.

Namun, dari pembahasan tanggapan pembaca novel Mariposa dalam situs Goodreads dapat diketahui bahwa sejumlah besar responden menganggap karya tersebut tidak memenuhi horizon harapan mereka. "[...] akan difilmkan, ditambah ada embel 2 mega best-seller di cover bukunya. Jadilah bukunya saya baca with high expectation. Tp ternyata setelah saya baca ..." (Anti). Fujiwara Asuka pun tidak melihat adanya kelebihan dalam novel Mariposa, "aku sama sekali ga paham kenapa banyak orang suka banget sama buku ini”. Ia tidak melihat kesesuaian di antara pandangan umum terhadap buku tersebut dengan realita yang ditemukan saat ia membacanya. Kesan tentang 'tidak adanya hal yang istimewa di dalam novel' juga dinyatakan Anyelir yang mengungkapkan "setelah saya membaca buku ini, saya tidak merasakan suatu kesan yang mendalam ataupun membekas dari cerita yang dibawakan penulis."

Hal serupa ditunjukkan Aprilia (2020) yang menganggap bahwa, selain karena ekspektasi yang tidak terpenuhi, faktor yang membuat ia tidak menyukai Mariposa adalah kesenjangan generasi, "memang usiaku yang enggak cocok buat baca teenlit lagi".

Leefe menutup komentarnya atas novel Mariposa dengan simpulan bahwa "kualitas sebuah karya tidak ditentukan dari jumlah pembacanya". Sementara itu, Dc dewi menyepakati pernyataan tersebut dengan menyatakan bahwa "jutaan pembaca belum tentu jadi jaminan ceritanya berkualitas [...]". Kedua tanggapan ini seperti menyiratkan adanya keraguan tersendiri tentang validitas atau kesahihan dari jumlah pembaca sebagai standar mutu karya sastra.

Dari seluruh pembahasan ini, terungkap bahwa responden sebagai representasi pembaca novel Mariposa menunjukkan tanggapan yang relatif negatif pada karya Luluk HF tersebut, terlepas dari klaim bahwa novel itu telah dibaca oleh puluhan juta pembaca Wattpad. Aprilia (2020) bahkan menegaskan lebih menyukai film Mariposa dibandingkan dengan novelnya.

Perbedaan tanggapan dan horizon harapan pembaca yang ditemukan dalam kajian ini relatif berbeda-beda. Hal ini sangat mungkin terjadi karena perbedaan pengetahuan pembaca tentang sastra, pengetahuan mereka tentang kehidupan, dan pengalaman mereka dalam membaca karya sastra. Asumsi ini dibuktikan dengan cetusan tanggapan para responden yang melakukan perbandingan terhadap novel Mariposa dengan karya-karya lain, seperti "adegan romancenya udah kayak cerita Wattpad lainnya" (Affiraaa), "the most annoying heroine yang pernah aku baca di buku-buku lain" (Fujiwara Asuka). Pernyataan-pernyataan tersebut memperlihatkan adanya pengetahuan dan pengalaman pembaca mengenai karya sastra.

Meskipun demikian, harapan masih disematkan para responden pembaca Mariposa, sebagaimana yang ditunjukkan Fanny, bahwa Mariposa 2, yang ditawarkan pengarang di halaman terakhir novel, harus lebih menampilkan konflik dan kelogisan dalam penceritaannya. Sementara itu, Anti menyampaikan harapan agar karya selanjutnya itu 
sebaiknya "lbh bisa menjelaskan latar belakang karakter dua tokoh utamanya shg pembaca bisa memahami knp mereka (terutama Acha) bisa seperti itu”. Hal ini menyiratkan kesan bahwa penilaian dan tanggapan atas suatu bacaan tidak bersifat final dan dapat dinegosiasikan.

Dari seluruh pembahasan mengenai tanggapan pembaca, horizon harapan, serta faktor-faktor yang menentukan perbedaan atau kesesuaian horizon harapan dalam meresepsi novel Mariposa ini memperlihatkan kecenderungan responden sebagai representasi populasi pembaca karya tersebut. Meskipun tidak diketahui latar belakang dan variabel pembaca (gender, umur, pendidikan, pekerjaan, dan sebagainya), namun afiliasi mereka pada situs Goodreads menunjukkan kebiasaan membaca yang relatif intens. Dengan demikian, pengetahuan pembaca mengenai ragam dan kualitas karya dapat dianggap berterima.

\section{PENUTUP}

Pembaca cenderung menanggapi secara negatif unsur-unsur intrinsik novel Mariposa, terutama alur yang dianggap terlalu lambat dan tokoh perempuan yang digambarkan terlalu agresif. Resepsi tersebut menyimpulkan bahwa cerita novel berkesan tidak realistis dan membosankan. Namun, sebagian pembaca menunjukkan apresiasi positif pada aspek humor dan tema romance yang disajikan pengarang.

Horizon harapan sebagian besar pembaca tidak sesuai dengan kenyataan yang ditampilkan oleh novel Mariposa. Responden menyatakan bahwa alasan ketertarikan membaca novel tersebut adalah karena rekomendasi teman serta klaim penerbit buku dan Wattpad yang menyebut Mariposa sebagai mega bestseller. Setelah membaca, para responden baru menyadari bahwa labelling yang hiperbolis tersebut tidak lain merupakan bentuk promosi dan strategi penjualan belaka sehingga tidak menjamin kualitas karya. Dalam konteks horizon harapan, juga terungkap bahwa ketertarikan pembaca dipicu oleh wacana bahwa novel Mariposa akan difilmkan dan dimainkan oleh para artis terkenal di kalangan remaja.

Sementara itu, faktor-faktor penyebab perbedaan tanggapan dan horizon harapan pembaca yang ditemukan dalam kajian ini adalah karena perbedaan pengetahuan tentang sastra, pengetahuan tentang kehidupan, dan pengalaman membaca karya sastra.

Penelitian ini belum tuntas sepenuhnya. Masih ada celah-celah penelitian lainnya yang dapat dilanjutkan seperti hasil pengalihwahanaan novel tersebut menjadi film serta resepsi penonton terhadap karya ekranisasi tersebut.

\section{DAFTAR PUSTAKA}

Admin. 2020. Film Mariposa (2020), Adaptasi Novel Wattpad Laris karya Luluk HF. Gramedia Blog. https://www.gramedia.com/blog/fak ta-film-mariposa-2020-zara/\#gref

Admin. 2021. Rekomendasi Novel Adaptasi Wattpad yang Paling Banyak Dibaca. Gramedia Blog. https://www.gramedia.com/blog/rek omendasi-novel-adaptasi-wattpadyang-paling-banyak-dibaca/\#gref

Amalina, J. N. 2021. Resensi Novel "Mariposa" Karya Luluk HF. Retrieved from https://www.kompasiana.com/jauhar ahnuramalina5532/60465e138ede48 
27ed6a8fe7/resensi-novel-mariposakarya-luluk-hf?page $=$ all

Aprilia. 2020. Cerita Remaja FenomenalReview Novel Mariposa. Retrieved from

https://catatanaprilia.wordpress.com /2020/03/08/cerita-remajafenomenal-review-novel-mariposa/

Arikunto. 2010. Prosedur Penelitian: Suatu Pendekatan Praktek. Jakarta: Rineka Cipta.

Dariannisa. 2020. Review Novel "Mariposa". Retrieved from https://kutipanannisa.wordpress.com /2020/03/10/review-nover-mariposa/

Dermawan, R. N. A., Cahya. 2014. Tanggapan Pembaca terhadap Novel Ayat-ayat Cinta Karya Habiburrahman El Shirazy: Tinjauan Resepsi Sastra. Caraka, 1(1), 14-22.

Fajriyah, H. M. 2021. The Effect of Social Media Instagram Promotion on The Sale of Mariposa Novel. Jurnal Manajemen Bisnis dan Kewirausahaan, 1(1), 1-10.

Fitriani, R., Priyadi, A.T., \& Seli, S. 2019. Perwatakan Tokoh dalam Novel Mariposa karya Luluk HF. Jurnal Pendidikan dan Pembelajaran Khatulistiwa, 8(10), 1-10.

Goodreads 2018. Re: Mariposa by Luluk $H F$. Message posted to https://www.goodreads.com/book/sh ow/43526083-mariposa

HF, L. 2018a. Mariposa. In. Retrieved from https://www.wattpad.com/story/101 689171-mariposa

HF, L. 2018b. Mariposa. Depok: Coconut Books.

Intan, T. 2019a. Le Petit Prince karya Antoine de Saint-Exupery dalam Tanggapan dan Horizon Harapan Pembaca. Kandai, 15(1), 87-100.

Intan, T. 2019b. Resepsi Remaja Perempuan Pembaca Novel Populer. Metahumaniora, 9(2), 157-167.
Jauss, H. R., Bahti, T., \& De Man, P. 2010. Toward an Aesthetic of reception. Minneapolis, Minn.: University of Minnesota Press.

Junus, U. 1985. Resepsi Sastra Sebuah Pengantar. Jakarta: Gramedia.

Khalid, S. 2020. Falcon Rilis Trailer Mariposa, Film Zara Adhisty dan Angga Yunanda. https://tirto.id/falcon-rilis-trailermariposa-film-zara-adhisty-danangga-yunanda-eyhs.

Lubis, R. H. N. 2019. Kemampuan Apresiasi Sastra Siswa SMA di Kota Medan. Medan Makna, 17(2), 171-179.

Mazaya, A. P. d. 2020. Analisis Struktur dalam Novel Mariposa karya Luluk $H F$. Paper presented at the Seminar Nasional Ilmu Pendidikan dan Multidisiplin 3.

Munaris. 2011. Resepsi Pembaca terhadap Unsur Fakta Cerita dalam Novel Ayat-Ayat Cinta Habiburrahman El Shirazi. Litera, 10(2), 171--182.

On. 2019. Review Novel Mariposa Karya Luluk HF. Retrieved from https://www.goresankata.com/2019/ 03/review-novel-mariposa-karyaluluk-hf.html

Pradopo, R. D. 1986. Estetika Resepsi, Teori dan Penerapannya. In $S$. Sutrisno (Ed.), Bahasa dan Budaya. Yogyakarta: Gadjah Mada University Press.

Pradopo, R. D. 2007. Beberapa Teori Sastra, Metode Kritik, dan Penerapannya. Yogyakarta: Pustaka Pelajar.

Rahajeng, D. 2020. Review + Resensi Novel Mariposa by Luluk HF (Semakin Dikejar, Semakin Menghindar). Retrieved from https://kehabisantintalagi.blogspot.c om/2020/02/review-resensi-novelmariposa-by-luluk_12.html 
Ratna, N. K. 2007. Estetika Sastra dan Budaya. Yogyakarta: Pustaka Pelajar.

Ratna, N. K. 2015. Teori, Metode, dan Teknik Penelitian Sastra. Yogyakarta: Pustaka Pelajar.

Saraswati, E. 2011. Resepsi Estetis Pembaca terhadap Novel Supernova Karya Dee. Atavisme, 14(2), 156169.

Sari, L. D. N. 2018. Resepsi Anak Usia SMP terhadap Novel Teenlit yang Berjudul Dalam Rinai Hujan Karya Arie Saptadji. Jurnal Ilmiah Bahasa dan Sastra, 5(1), 13--24.
Segers, R. T. 1978. The Evaluation of Literary Texts. Lisse: The Peter de Ridder Press.

Teeuw, A. 1984. Sastra dan Ilmu Sastra: Pengantar Teori Sastra. Jakarta: Dunia Pustaka Jaya.

Vodicka, F. 1964. The History of The Echo of Literary Words. In P. L. Garvin (Ed.), A Prague School Reader on Esthetics, Literary Structure and Style. Washington.

Wulan, N. 2013. Does Phallic Masculinity Still Matter?: Masculinities in Indonesian Teenlit During the PostReformasi Periode (1998-2007). The Journal of Men's Studies, 21(2), 149161. doi:10.3149/jms.2102.149. 